\title{
The Influence of Structural Innovation on Organizational Performance from a Dynamic Capability Perspective: An Empirical Study on HEM Enterprises
}

\author{
Xiaoran Li $(\mathbb{D}$, Chunsheng Shi $(\mathbb{D}$, and Wei Jin $\mathbb{1}$ \\ School of Economics and Management, Harbin Institute of Technology, Harbin, China \\ Correspondence should be addressed to Xiaoran Li; xiaoranli1002@163.com
}

Received 4 February 2021; Revised 22 December 2021; Accepted 13 January 2022; Published 31 January 2022

Academic Editor: Anna M. Gil-Lafuente

Copyright (c) 2022 Xiaoran Li et al. This is an open access article distributed under the Creative Commons Attribution License, which permits unrestricted use, distribution, and reproduction in any medium, provided the original work is properly cited.

\begin{abstract}
In the current rapidly changing environment, this article explores the influence mechanism and path of structural innovation on organizational performance of enterprises from a perspective of dynamic capability. The empirical study of 362 HEM enterprises shows that structural innovation has a significant direct impact on organizational performance, and the two dimensions of dynamic capability, namely, absorptive capability and transformative capability, not only play an independent intermediary role in the relationship between structural innovation and organizational performance but also play a chain intermediary role.
\end{abstract}

\section{Introduction}

Currently, the rapid development of technology, shrinking consumer market and extremely unstable trade market [1], these external environmental factors have put forward higher requirements for the development of enterprises. At present, there are many researches on technological innovation of enterprises, but in many enterprises, technological innovation has only brought short-term performance growth. This is because in such a highly dynamic environment, extensive management can no longer meet the growth needs of enterprises. Therefore, organizational structure, as the framework of an enterprise, has attracted the renewed attention of many scholars and managers, which is the foundation of operation and management. From earliest linear structure to division system, and then network structure [2], the continuous changes of the external environment make the structural innovation more and more flat, decentralized, informal and adaptable [3]. Many enterprises have carried out organizational innovation activities and adopted a more flat, decentralized and responsive organizational structure.

There has been no consistent view on the impact of structural innovation on organizational performance, which has led many enterprises to pay less attention to structural innovation. Early studies generally believe that structural innovation improves organizational performance by reducing management costs, improving management efficiency and employee satisfaction [4-7]. However, whether saving cost or improving work efficiency is analyzed from a static perspective, and the performance improvement is limited. It is not enough to explain the important role of structural innovation in organizational performance in the current dynamic environment. Then, how does structural innovation affect organizational performance? How to understand the relationship between structural innovation and organizational performance from a dynamic perspective? These are the issues that this article wants to discuss. Related works on structure and performance is shown in Table 1.

Recently, some scholars discuss the relationship between organizational structure and organizational performance from a dynamic perspective, such as Zhang Guang-lei (2011) separately discussed the influence of organizational structure on innovation performance through the improvement of absorptive capability and transformative capability $[8,9]$, but he only mentioned one aspect of knowledge, not explained the complete process; Wang Tao (2018) proposed that innovative organizational structure enhanced the 
TABle 1: Antecedents of structure and performance.

\begin{tabular}{lcc}
\hline $\begin{array}{l}\text { Research } \\
\text { perspective }\end{array}$ & Reference \\
\hline Static perspective & $\begin{array}{c}\text { Reduce management costs } \\
\text { Improve management efficiency } \\
\text { Improve employee satisfaction } \\
\text { Knowledge absorption knowledge } \\
\text { transfer }\end{array}$ & Child, J. (1972), Dawson, P. (1994), Mabey, C. (1995), Ogbonna E (2003) \\
$\begin{array}{l}\text { Dynamic } \\
\text { perspective }\end{array}$ & OECD (2005) \\
\hline
\end{tabular}

dynamic capability of enterprises and further improved international performance [10], and demonstrates that dynamic capability seize the opportunity to reset resources to improve performance in complex external environment, but he lacked a detailed analysis of the process of dynamic capability. Therefore, based on previous studies, this article introduces dynamic capability theory, constructs a model of "structure-capability-performance", and further discusses the mechanism and path of structural innovation on organizational performance through deconstructing dynamic capabilities, the snapshot of the research steps is as shown in Figure 1.

\section{Theoretical Basis and Research Hypothesis}

2.1. Dynamic Capability. Dynamic capability is first put forward by Teece and Pisano (1997) based on the resourcebased view, immediately caused widespread concern. The theory of dynamic capability make up for the resource-based view that emphasizes the internal resources and lack attention to external environment and emphasizes how to obtain resources and capabilities in a dynamic environment to maintain a sustainable competitive advantage. Teece defined dynamic capability as "the firm's ability to integrate, build, and reconfigure internal and external competences to address rapidly changing environment" [11], Zollo and Winter (2002) defined dynamic capability as "a learned and stable pattern of collective activity through which the organization systematically generates and modifies its operating routines in pursuit of improved effectiveness" [12]. Although at present there is no agreement about the concept of dynamic capability, scholars generally agree that dynamic capability is a kind of "higher-order" ability that can change ordinary capabilities. Ordinary capabilities of organization are considered to be "zero-level" capabilities, which are used to effectively develop existing resources, while dynamic capability is considered to be "first-level" capability, and their main role is to effectively develop new resources [13]. The "dynamic" in dynamic capability means that in order to adapt to the external environment, companies must constantly update their own capabilities, and the process of dynamic capability changing capabilities is actually the result of an update of its own knowledge system. Therefore, with the deepening of research, many scholars have interpreted dynamic capability from the perspective of knowledge and evolution. Nielsen (2006) combined dynamic capability with knowledge management activities, and classified dynamic capability into three capabilities: knowledge development,

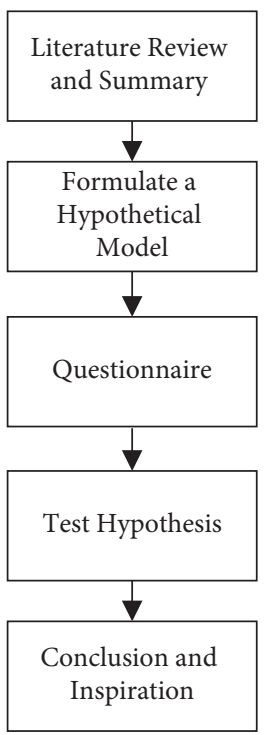

Figure 1: Snapshot of the research.

knowledge combination and knowledge use [14]. Chinese scholars Wang Jingna (2009) on the basis of Winter and Teece, from the perspective of knowledge, pointed out that dynamic capability is the ability to acquire knowledge from the outside by identifying market opportunities, and internally integrate and reconfigure existing knowledge and external new knowledge, and then create new resources and capabilities to meet the environmental requirements of organization [15]. Essentially speaking, resources and capabilities are both a kind of knowledge. The introduction of the knowledge perspective makes the connotation of dynamic capability clearer and the object more focused, which transform dynamic capability from a variety of resources, capabilities, processes or conventions to the specific process to absorb, integrate and create knowledge. It significantly improved the observability and operability [16], and is powerful in promoting the in-depth study of dynamic capability. Therefore, this article adopts the definition of dynamic capability by Wang Jingna and based on the research of Pandza [16] and CL. Wang [17], according to the different sources of knowledge, divides dynamic capability into two sub-dimensions: absorptive capability and transformative capability. Absorptive capability refers to the ability of an enterprise to identify and absorb external knowledge and transform it into internal new knowledge or resources. It is a process of transforming external knowledge into internal knowledge. Transformative capability refers to the ability of 
an enterprise to integrate and apply existing internal knowledge to form new knowledge or resources. It is a process of re-integration and creation of internal knowledge to form valuable new knowledge [18].

\subsection{Structural Innovation and Organizational Performance.} Structural innovation is a new organizational structure developed to change the way of organizational coordination, communication and contact as well as the distribution form of responsibilities and obligations. The new organizational structure needs to maintain dynamic coordination with strategy, culture, process and technology [19]. Structural innovation is an adjustment and optimization made to adapt to the internal and external environment of an organization. In the current highly dynamic market environment, structural innovation tends to be flat, decentralized and flexible. Structural innovation brings new information transmission methods and decision-making methods for enterprises, enabling enterprises to adapt and respond to the environment more quickly. Moreover, the reduction of management level and the increase of management range avoid meaningless management consumption, and at the same time fully mobilize the initiative of the organization, improve the overall work efficiency, reduce the operation cost, and improve organizational performance. From the perspective of transaction cost theory, structural innovation reduces the degree of enterprise centralization and is more inclined to collective decision-making, which can reduce the impact caused by managers' "bounded rationality" and "opportunism", thereby reducing transaction costs of enterprises to promote organizational performance [2]. Based on the above analysis, the hypothesis $\mathrm{H} 1$ is proposed.

$\mathrm{H} 1$ : structural innovation has a positive impact on organizational performance.

2.3. Intermediation Role of Dynamic Capabilities. In previous studies, although scholars believe that structural innovation has an impact on organizational performance, it is generally believed that the direct impact is less and more of an intermediary effect. With the acceleration of technological update and the increasing volatility of market, it is not enough to consider the relationship between structural innovation and organizational performance from the static perspective of cost reduction and efficiency improvement. Instead, it is necessary to explore the relationship between organizational structure innovation and organizational performance from the perspectives of the dynamic development of knowledge and long-term learning mechanisms. Dynamic capability is such a kind of ability, which can make enterprises respond effectively to the demand of external environment by constantly adjusting and changing the operation capability and resource base, so as to obtain continuous competitive advantage and improve performance. Organizational structure is the micro foundation of dynamic capability [20]. Further, structural innovation changes the way enterprises acquire knowledge, broadens the circulation channels of knowledge in enterprises, and improves the efficiency of knowledge acquisition and transfer. And dynamic capability is a process of knowledge renewal and reorganization. Therefore, the flat, decentralized and flexible structure brought by structural innovation can enhance the dynamic capability of enterprises, and the new resources and abilities formed by the dynamic capability can make enterprises adapt to the current environment, meet the market demand, and improve organizational performance. In order to further study the role of dynamic capability, this article divides dynamic capability into absorptive capability and transformative capability. Absorptive capability and transformative capability are both internal capabilities, but absorptive capability is outward-looking, and transformative capability is inward-looking [18].

The structural innovation of enterprises can enhance the absorptive capability contained in the dynamic capability through both formal and informal channels. On the one hand, enterprises can set up separate departments or increase their job functions to strengthen the collection of information and industrial knowledge about the external environment. This formal and institutionalized function can better guarantee and expand the source channels of information and knowledge, enhance the perception and reception of the external environment, and make it easier for the internal absorption and transformation of external knowledge. On the other hand, the flattening and decentralization of the organizational structure can increase the personal enthusiasm and participation of employees, making each employee a knowledge receiver and a knowledge releaser, accelerating the flow and dissemination of knowledge [21], and then make the external knowledge quickly converted into applicable internal knowledge, so the absorptive capacity of enterprises can be improved. The rapid digestion, integration, and application of external knowledge can help enterprises gain the ability to quickly respond to markets and opportunities for development and win more profits and market shares. Based on the above analysis, the hypothesis $\mathrm{H} 2$ is proposed.

$\mathrm{H} 2$ : absorptive capability of enterprises plays an intermediary role in the relationship between structural innovation and organizational performance.

Transformative capability in dynamic capability allows enterprises to apply internal knowledge to novel and unanticipated applications and ultimately trigger the progress of new knowledge while making full use of existing knowledge to form new capabilities or resources [18]. Structural innovation brought flat, decentralized, and informal structure mode to enterprises, which can break the shackles brought by traditional structure to departments and individuals for a long time. The reduced management level and widen management range can effectively cut down the cost of vertical communication and increase communication and exchanges between departments, making the channels of knowledge circulation more diversified. It is helpful for cross-departmental knowledge resources to be coordinated and integrated within the enterprise. The collection and integration of multiple knowledge can maximize the application of internal knowledge and greatly increase the possibility of triggering new knowledge, which means that the transformative capability is effectively improved. The 
new knowledge and resources brought by transformative capability can meet the requirements of the external environment on the enterprises, make up for market vacancies, meet market demands, and promote organizational performance. Based on the above analysis, hypothesis $\mathrm{H} 3$ is proposed.

H3: the transformative capability plays an intermediary role in the relationship between structural innovation and organizational performance.

Dynamic capability is a concept with internal logic level, and there is a certain evolutionary and progressive relationship [20]. From the perspective of the micro process of knowledge system update, there are two independent and cohesive paths for dynamic capabilities, which are identifying and learning external knowledge to form internal knowledge and transforming and integrating internal knowledge. After the external knowledge is absorbed by the enterprise, it can be further integrated with other internal knowledge to form new knowledge. From another macro perspective, there is a certain progressive relationship between absorptive capability and transformative capability. Organizational resources and capabilities formed by absorptive capability can also be integrated with other internal resources to form new resources and capabilities to meet the needs of enterprises. Therefore, absorptive capability not only directly affects the enterprise, but also affects the operation and performance of the enterprise through transformative capability. Based on the above analysis, hypothesis $\mathrm{H} 4$ is proposed.

H4: absorptive capability and transformative capability play a chain intermediary role between structural innovation and organizational performance.

\section{Research Design}

3.1. Data Collection. The research object of this article is HEM (High-end Equipment Manufacturing) enterprises. HEM is an industry that manufactures advanced industrial equipment with high technology and high value-added. HEM enterprises are in high-end part of the value chain, which not only have characteristics of high-tech and knowledge-intensive, but also has the scale and complexity of manufacturing industry, so the study of HEM enterprises has an important significance. According to the "Outline of the thirteenth five-year Plan for National Economic and Social Development of the People's Republic of China" issued in 2016, the key development of HEM industries including eight aeras of: aerospace equipment, marine engineering equipment and high-tech ship, advanced rail transit equipment, high-end CNC machine tools, robotic equipment, modern agricultural machinery equipment, high-performance medical equipment, and advanced chemical complete sets. This article collects data by questionnaire survey of enterprises in the above eight industries. The research work began in June 2018 and ended in January 2019. The research enterprises are mainly located in Harbin, Beijing, Shenzhen, Shanghai, Shenyang and other places, and the respondents of the questionnaire are the middle and senior managers of the enterprises. This time, a total of 472 questionnaires were issued, and a total of 381 questionnaires were returned, with a recovery rate of $80.72 \%$, of which 362 were valid questionnaires, with a recovery rate of $76.70 \%$.

3.2. Measurement of Variables. This article refers to and draws on some mature scales, and adopts two-way translation to ensure the accuracy of concept translation. The scale has high reliability and validity. The whole scale is measured by LIKERT 5-point scale, and 1-5 successively represents "complete disagreement" to "complete agreement". Structural innovation, dynamic capability and organizational performance were measured by multiple items respectively. Structural innovation variables refer to the research of Zhang Guanglei [8] and Huang [21] et al., and the evaluation from the four aspects of flattening, decentralization, departmental communication and feedback speed is taken as the topic measurement of structural innovation. Dynamic capability variables were measured from two dimensions of absorptive capability and transformative capability using CL. Wang et al. 's scale [18], with 3 items of absorptive capability and 4 items of transformative capability. Organizational performance variables refer to the scale of Lee and Choi [22], which has three items in total and adopts the self-evaluation method of multiple factors rather than a single factor to measure organizational performance. Organization performance in addition to under the influence of structural innovation and dynamic capability, may also be affected by the age, size and so on enterprise features, in order to reduce the influence of above factors on the organizational performance, this article will control the above variables, taking the natural logarithm of the age, the size of the enterprise is expressed by the number of employees, and taking the natural logarithm of the number of employees. As shown in Table 2, the factor load of all variables is greater than 0.7 , Cronbach's value of all variables is greater than 0.8 , and the square root of AVE of all variables is shown in the diagonal line in Table 3 Therefore, this scale has good reliability and validity.

\section{Data Analysis and Results}

4.1. Common Method Deviation Test. SPSS23.0 application software, put together all variables, principal component factor analysis of the isolated from variable not rotating factor, the test results have multiple eigenvalues greater than 1 common factor, the biggest characteristic root factors can explain $37.06 \%$ of the variance, not more than $40 \%$ of the critical value, so the common method biases in the acceptable range.

4.2. Confirmatory Factor Analysis. The confirmatory factor analysis with MPLUS7.4 showed that the fitting effect of the four-factor model was the best, $2 / \mathrm{df}=1.304<3$, $\mathrm{SRMR}=0.036<0.05, \quad \mathrm{TLI}=0.970>0.9, \quad \mathrm{CFI}=0.977>0.9$, RMSEA $=0.057<0.08$, and the fitting indexes of the model met the requirements. 
TABLE 2: Reliability and validity of variables.

\begin{tabular}{|c|c|c|c|}
\hline Variable & Subject outline & $\begin{array}{l}\text { Factor } \\
\text { loading }\end{array}$ & Cronbach's alpha \\
\hline \multirow{4}{*}{ Structural innovation } & SI1: the enterprise is flatter than before & 0.779 & \multirow{4}{*}{0.823} \\
\hline & SI2: employees have more decision-making power & 0.768 & \\
\hline & SI3: more work communication between departments & 0.787 & \\
\hline & SI4: feedback on work is faster than before & 0.774 & \\
\hline \multirow{3}{*}{ Absorptive capability } & $\begin{array}{c}\text { A1: the company regularly searches the market for new knowledge and } \\
\text { resources }\end{array}$ & 0.863 & \multirow{4}{*}{0.894} \\
\hline & A2: companies can learn new knowledge and resources quickly & 0.836 & \\
\hline & A3: the company can apply new knowledge to new products & 0.846 & \\
\hline \multirow{4}{*}{$\begin{array}{l}\text { Transformative } \\
\text { capability }\end{array}$} & T1: employees are encouraged to provide their own methods and opinions & 0.918 & \\
\hline & $\begin{array}{l}\text { T2: encourage employees to understand the knowledge and skills relevant to } \\
\text { their work in the enterprise }\end{array}$ & 0.926 & \multirow{3}{*}{0.936} \\
\hline & $\begin{array}{c}\text { T3: encourage employees to challenge outdated practices and try new ways of } \\
\text { doing things }\end{array}$ & 0.929 & \\
\hline & T4: it provides a lot of support for employees' attempts at innovation & 0.893 & \\
\hline \multirow{3}{*}{$\begin{array}{l}\text { Organizational } \\
\text { performance }\end{array}$} & P1: higher profit compared with other competitors & 0.806 & \multirow{3}{*}{0.869} \\
\hline & P2: a larger market share compared with other competitors & 0.772 & \\
\hline & P3: compared with other competitors, profit grows faster & 0.867 & \\
\hline
\end{tabular}

TABLE 3: Correlation coefficient of variables $(N=362)$.

\begin{tabular}{|c|c|c|c|c|}
\hline Variables & Structural innovation & Absorptive capability & Transformative capability & Organizational performance \\
\hline Structural innovation & 0.733 & & & \\
\hline Absorptive capability & $0.448^{* * *}$ & 0.858 & & \\
\hline Transformative capability & $0.504^{* * *}$ & $0.552^{* * *}$ & 0.892 & \\
\hline Organizational performance & $0.465^{* * *}$ & $0.521^{* * *}$ & $0.613^{* * *}$ & 0.837 \\
\hline Mean & 3.325 & 2.348 & 3.345 & 3.129 \\
\hline Standard & 0.957 & 0.936 & 1.052 & 1.151 \\
\hline
\end{tabular}

Note: ${ }^{*} p<0.05,{ }^{* *} p<0.01$, and ${ }^{* * *} p<0.001$. The bold diagonal data are the AVE square root of the corresponding variable.

4.3. Descriptive Statistical Analysis. The mean value, standard deviation and correlation coefficient matrix of variables are shown in Table 3. According to the data in the table, structural innovation is significantly positively correlated with dynamic capability and organizational performance, and the correlation analysis results can preliminarily obtain the relationship between variables.

4.4. Hypothesis Testing. In this study, MPLUS7.4 is used to conduct structural equation modeling and verify the relationship between variables. The normalized path coefficient and significance of the structural equation are shown in Figure 2. First, hypothesis 1 is tested, with structural innovation as an independent variable and organizational performance as a dependent variable. The results show that structural innovation has a significant positive impact on organizational performance $(\beta=0.184, P<0.05)$, and hypothesis 1 is valid.

Then the mediating effect is tested by maximum likelihood method and percale bootstrap $(=5000)$ with deviation correction, and the direct effect, indirect effect and total effect are as shown in Table 4 . The indirect effect of structural innovation on organizational performance through absorptive capability is $0.133(P<0.001)$, and the $95 \%$ level confidence interval CI is $(0.065,0.203)$ excluding 0 . Hypothesis 2 is established. The indirect effect of structural innovation on organizational performance through

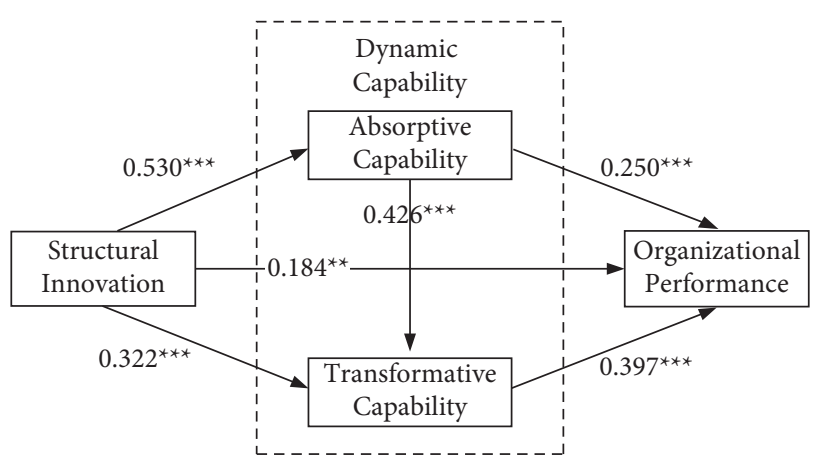

Figure 2: Structural equation test results.

transformative capability is $0.128(P<0.001)$, and the confidence interval CI of $95 \%$ level is (0.070, 0.199), excluding 0 . Hypothesis 3 is valid. The two dimensions of dynamic capabilities, the chain mediation of absorptive capability and transformative capability, has an indirect effect value of $0.089(p<0.001)$ between structural innovation and organizational performance, the level of $95 \% \mathrm{CI}$ is $(0.054,0.127)$, not including 0 , hypothesis 4 is established. Therefore, the total indirect effect of structural innovation on organizational performance through dynamic capabilities is 0.350 , and the total effect of structural innovation on organizational performance is the sum of direct and indirect effects of 0.534 . 
TABle 4: Total effect, indirect effect, and direct effect.

\begin{tabular}{|c|c|c|c|c|c|}
\hline & \multirow[t]{2}{*}{ Effect } & \multicolumn{2}{|c|}{$\begin{array}{l}\text { Bias-corrected } \\
95 \% \text { CI }\end{array}$} & \multicolumn{2}{|c|}{$\begin{array}{l}\text { Percentile } 95 \% \\
\text { CI }\end{array}$} \\
\hline & & Lower & Upper & Lower & Upper \\
\hline \multicolumn{6}{|c|}{ Total effect } \\
\hline SI-P & 0.534 & 0.434 & 0.627 & 0.432 & 0.626 \\
\hline \multicolumn{6}{|c|}{ Indirect effect } \\
\hline $\mathrm{SI}-\mathrm{A}-\mathrm{P}$ & 0.133 & 0.071 & 0.211 & 0.065 & 0.203 \\
\hline $\mathrm{SI}-\mathrm{T}-\mathrm{P}$ & 0.128 & 0.072 & 0.202 & 0.07 & 0.199 \\
\hline $\mathrm{SI}-\mathrm{A}-\mathrm{T}-\mathrm{P}$ & 0.090 & 0.058 & 0.133 & 0.054 & 0.127 \\
\hline \multicolumn{6}{|c|}{ Direct effect } \\
\hline SI-P & 0.184 & 0.058 & 0.311 & 0.059 & 0.312 \\
\hline
\end{tabular}

\section{Conclusions and Implications}

5.1. Conclusion. This article takes HEM enterprises as the research object, conducts empirical analysis of data samples, discusses the mechanism of structural innovation on organizational performance from the perspective of dynamic capability, and draws the following conclusions: (1) Structural innovation has a direct positive impact on organizational performance; (2) as two dimensions of dynamic capability, absorptive capability and transformative capability play mediating roles in the relationship between structural innovation and organizational performance; and (3) absorptive capability and transformative capability not only play an independent mediating role, but also play a chain mediating role in the relationship between structural innovation and organizational performance.

5.2. Theoretical Contribution. Firstly, this article expounds the connotation and dimension division of dynamic capability. From the perspective of knowledge, it unifies the connotations of resources, capabilities, and conventions involved in dynamic capability, and points out that the role of dynamic capability is a process of absorbing, integrating and creating knowledge, and dividing dynamic capability into absorptive capability and transformative capability according to different sources of knowledge. It makes dynamic capability more convenient for observation and application, and helps further study of dynamic capability.

Second, this article enriches the research on the relationship between structural innovation and organizational performance. There have always been two views on the relationship between structural innovation and organizational performance, one is the direct impact, and the other is the indirect impact. This research proves through empirical analysis that organizational structure innovation has a direct positive impact on organizational performance, but the impact is relatively small. Therefore, it is of great significance to explore the relationship between organizational structure innovation and organizational performance from more perspectives.

Third, the article clarifies the influence path of structural innovation on organizational performance in HEM enterprises. In the current complex market environment, we have a clearer understanding of the impact mechanism of structural innovation on organizational performance from the perspective of dynamic capability. This study points out that there are three paths for structural innovation to affect organizational performance: structural innovation $\longrightarrow$ absorptive capability $\longrightarrow$ organizational performance, structural innovation $\longrightarrow$ transformative capability $\longrightarrow$ organizational performance, and structural innovation $\longrightarrow$ absorptive capability $\longrightarrow$ transformative capability $\longrightarrow$ organizational performance. It provides new ideas for indepth study of the impact of organizational structure innovation on organizational performance.

5.3. Management Enlightenment. First, actively carry out structural innovation. At present, China generally attaches importance to technological innovation and ignores structural innovation. The research show that structural innovation also plays an important role in organizational performance, so that enterprises can draw lessons from experience, combined with their own actual situation, according to the development needs to adjust organizational structure, appropriately reduce the management level, increase the scope of management, give more autonomy to each department, strengthen interdepartmental communication, improve the response speed of enterprises, and make the organizational structure flatter, decentralized and flexible. These innovative activities can effectively improve the operational efficiency of enterprises, and at the same time promote the growth of dynamic capabilities of enterprises, so that enterprises have the ability to continuously updated itself, maintain the competitive advantage, and improve the organizational performance in the rapidly changing environment.

Second, from the perspective of dynamic capability, enhancing the absorptive capability and transformative capability of enterprises is also a way to achieve organizational performance. In addition to structural innovation, on the one hand, we can strengthen individual's perception of the external-level employees, increase opportunities for employees to go out for learning, training, research, and communication, and allow employees to acquire more external knowledge. At the organizational level, we can also establish routines for regular collection and sorting of external knowledge and information or increase the function of processing external information to strengthen the entire enterprise's attention and sensitivity to external knowledge and information, thereby enhancing the company's absorptive capability. On the other hand, it is possible to promote the internal integration and reorganization of information and knowledge by appointing transformational managers, internal rotations, regular internal communication, perfect file management, create an open learning and communication atmosphere, and establish a system that encourages innovation, thereby strengthening transformative capability, and further promoting performance.

5.4. Limitations and Future Research. Although this article demonstrates the impact of structural innovation on organizational performance from the perspective of dynamic capability and validates it through empirical research, there 
are still some limitations in the research: first, the concept of dynamic capabilities has always been controversial. Due to the different dimensions of dynamic capability, the intermediary path of dynamic capability is not unique, and more exploration is needed. Second, the organizational performance in the questionnaire includes three items, which may not be a comprehensive representation of organizational performance, and the connotation of organizational performance can be more perfect in future research.

\section{Data Availability}

The data used to support the findings of this study are available from the corresponding author upon request.

\section{Conflicts of Interest}

The authors declare that they have no conflicts of interest.

\section{References}

[1] G. Shao and Z. Luan, "Research on the industrial transformation and upgrading in the context of new normal," Journal of Technical Economics \& Management, vol. 235, no. 5, pp. 94-97, 2016.

[2] W. Wu, B. Wu, and Q. Xu, "The course and law of enterprise organizational structure innovation," Scientific Management Research, vol. 17, no. 6, pp. 1-4, 1999.

[3] E. Ogbonna and L. C. Harris, "Innovative organizational structures and performance," Journal of Organizational Change Management, vol. 16, 2003.

[4] J. Child, "Organizational structure, environment and performance: the role of strategic choice," Sociology, vol. 6, no. 1, pp. 1-22, 1972.

[5] P. M. Dawson, Organizational Change: A Processual approach, Paul Chapman Publishing, London, UK, 1994.

[6] C. Mabey and G. Mallory, "Structure and culture change in two UK organisations: a comparison of assumptions, approaches and outcomes," Human Resource Management Journal, vol. 5, no. 2, pp. 28-45, 1994.

[7] OECD, The Measurement of Scientific and Technological Activities Oslo Manual Guidelines for Collecting and Interpreting Innovation Data, OECD and EUROSTAT, Paris, France, 3rd edition, 2005.

[8] G. Zhang, L Shan-shi, and S Hong-yan, "Organizational structure, knowledge transfer channel, and R\&D team innovation performance: an hi-tech enterprises-based empirical study," Studies in Science of Science, vol. 29, no. 8, pp. 1198-1206, 2011.

[9] G. Zhang, L Shan-shi, and J. Peng, "Organizational structure, knowledge absorptive capacity and R\&D team's innovation performance P: a cross-level test," R \& D Management, vol. 24, no. 2, pp. 19-27, 2012.

[10] T. Wang, Y. Lu, and L. Jin, "The effect of structural organicity on reverse internationalization performance: a perspective of dynamic capabilities," Chinese Journal of Management, vol. 15, no. 2, pp. 174-182, 2018.

[11] D. J. Teece, G. Pisano, and A. Shuen, "Dynamic capabilities and strategic management," Strategic Management Journal, vol. 18, no. 7, pp. 509-533, 1997.

[12] M. Zollo and S. G. Winter, "Deliberate learning and the evolution of dynamic capabilities," Organization Science, vol. 13, no. 3, pp. 339-351, 2002.
[13] J. G. March, "Exploration and exploitation in organizational learning," Organization Science, vol. 2, no. 1, pp. 71-87, 1991.

[14] A. Paarup Nielsen, "Understanding dynamic capabilities through knowledge management," Journal of Knowledge Management, vol. 10, no. 4, pp. 59-71, 2006.

[15] J. Wang and S. Feng, "A study of the dimensionality of dynamic capability based on knowledge management views," Scientific Management Research, vol. 27, no. 6, pp. 71-75, 2009.

[16] K. Pandza and R. Holt, "Absorptive and transformative capacities in nanotechnology innovation systems," Journal of Engineering and Technology Management, vol. 24, no. 4, pp. 347-365, 2007.

[17] C. L. Wang and P. K. Ahmed, "Dynamic capabilities: a review and research agenda," International Journal of Management Reviews, vol. 9, no. 1, pp. 31-51, 2007.

[18] C. L. Wang, C. Senaratne, and M. Rafiq, "Success traps, dynamic capabilities and firm performance," British Journal of Management, vol. 26, no. 1, pp. 26-44, 2015.

[19] J. Liu, "The system behavior and its complexity of organizational innovation in the information technology--based environment," Studies in Science of Science, vol. 27, no. 4, pp. 598-603, 2009.

[20] D. J. Teece, "Explicating dynamic capabilities: the nature and microfoundations of (sustainable) enterprise performance," Strategic Management Journal, vol. 28, no. 13, pp. 1319-1350, 2007.

[21] X. Huang, M. M. Kristal, and R. G. Schroeder, "The impact of organizational structure on mass customization capability: a contingency view," Production and Operations Management, vol. 19, no. 5, pp. 515-530, 2010.

[22] H. Lee and B. Choi, "Knowledge management enablers, processes, and organizational performance: an integrative view and empirical examination," Journal of Management Information Systems, vol. 20, no. 1, pp. 179-228, 2003. 